\title{
Perspectivas de desenvolvimento sustentável para o setor florestal na América Latina
}

\author{
ALEXANDRE GRIMALDI DE CASTRO \\ E SÉRGIO MORROT
}

$\mathrm{E}$

STE ENSAIO OBJETIVA ANALISAR as perspectivas de inserção do conceito de desenvolvimento sustentado nas fases de planejamento e operação de atividades de exploração florestal do setor de papel e celulose na América Latina. Não houve preocupação em quantificar determinados eventos ou em analisar processos e casos específicos, concentrando-se maior atenção nos aspectos teóricos e conceituais correlatos. Procurou-se analisar o atual modelo de exploração florestal, as principais implicações quanto à manutenção de recursos naturais e qualidade ambiental, bem como algumas alternativas para procedimentos de transição e estabelecimento de nova sistemática de desenvolvimento sustentável.

Tecnicamente, o conceito de sustentabilidade está relacionado à capacidade de um sistema em propiciar meios de subsistência a determinada população em intervalos espaço/temporais definidos. De forma simplificada, um sistema auto-sustentado pode ser caracterizado por apresentar um equilíbrio dinâmico balanço espaço/temporal - entre suas necessidades e os meios de sustentação necessários. Especificamente quanto ao setor de papel e celulose, a implementação de um programa de desenvolvimento sustentado está relacionada à gestão da base de recursos e à interação com os agentes sociais associados aos processos de produção de matéria-prima, transformação e comercialização dos produtos.

O conceito de desenvolvimento sustentado pode ainda ser analisado quanto a seus aspectos ambiental (biofísica) e antrópico. O primeiro representa a avaliação integrada dos processos produtivos e ambientais, as estratégias de manejo ambiental/florestal empregadas e a conservação e utilização racional dos recursos naturais. O segundo trata especificamente dos componentes políticos, sociais e culturais do ambiente, procurando-se a incorporação desses fatores na elaboração de estratégias de desenvolvimento sustentável. Objetiva a compreensão dos processos produtivos em escala mais ampla, com o resgate e a conservação de valores culturais e ambientais em suporte a atividade específica do setor - manejo e conservação dos recursos florestais. 
Questões de cunho social assumem feição mais crítica quando analisadas economias e sociedades latino-americanas. Estas caracterizam-se por ter historicamente excluído determinados agentes e parcelas da sociedade durante processo de desenvolvimento regional. A implementação de Programas de Desenvolvimento Sustentado na região requer, assim, a integração de todos os elementos da sociedade diretamente afetados, de forma a conferir consistência política ao processo. O não-envolvimento de determinada parcela da sociedade implica riscos acentuados a médio e longo prazos, tendo em vista o empobrecimento sócio-econômico e a possibilidade de agravamento substancial das crises políticas, sociais e econômicas.

A aplicação do conceito de desenvolvimento sustentado representa estratégia semelhante a medicina ou odontologia preventivas. Procura-se antever a incidência de determinado problema com o estabelecimento de estratégia proativa. À semelhança dos resultados espelhados pela área de saúde, os custos globais tornam-se gradativamente menores em função do aumento progressivo da produtividade e da redução dos gastos em ações acauteladoras e corretivas. Tal fato, por si só, justifica a operacionalização deste conceito. Ademais, a melhoria dos níveis de qualidade de vida tende a propiciar condições objetivas de aprimoramento do próprio processo produtivo. Mais do que truísmos, estas afirmações correspondem a resultados derivados da experiência em outros setores produtivos, a exemplo do setor automobilístico japonês, o qual deve sua capacidade produtiva e competitiva, em grande parte, à redução global dos custos sociais e concomitante melhoria das condições de vida das populações direta e indiretamente envolvidas.

Dois fatores impulsionam, adicionalmente, a adoção de estratégias de desenvolvimento sustentado para o setor de papel e celulose:

- aumento crescente da pressão social ocasionada pela transferência para a sociedade de externalidades intrínsecas e extrínsecas a este setor produtivo; e

- necessidades objetivas de inovação tecnológica, as quais representam a projeção de vantagens competitivas a médio e longo prazos.

Embora díspares em interesses e reflexos imediatos, estas questões apresentam íntima associação quando analisadas em suas perspectivas históricas de desenvolvimento.

Considerando um setor produtivo específico, caso seja epistemologicamente possível e conceitualmente coerente, a idéia de desenvolvimento sustentado estabelece as bases operacionais sobre as quais são projetadas soluções de continuidade mais favoráveis. Um programa de desenvolvimento sustentado para o setor 
florestal é concebido de forma a permitir a manutenção dos processos produtivos por períodos mais longos e a custos relativamente estáveis. Tal assertiva não deve implicar, necessariamente, aumento constante dos níveis de produtividade, mas, sobretudo, otimização dos processos envolvidos.

\section{Condicionantes ambientais no âmbito da América Latina}

A exploração florestal adquire contornos específicos de acordo com os ecossistemas e sistemas de paisagens considerados. Florestas de produção instaladas em regiões de clima temperado apresentam condicionantes ambientais (driving forces) características e diferenciadas daquelas encontradas em regiões tropicais. A observação dos sistemas de florestas naturais nestas regiões nos remete a estabelecer igual paralelo para sistemas introduzidos ou diretamente manejados pelo homem. A implantação de florestas de produção em diferentes zonas climáticas assume características próprias, demandando ações de planejamento e manejo ambiental particulares.

Sistemas temperados são reconhecidos pela reduzida diversidade estrutural e padrões funcionais menos complexos - menores níveis de incerteza. Sistemas tropicais, ao contrário, são representados por mosaicos estruturais de maior complexidade. O principal impacto na definição de planos de manejo é observado pela necessidade de reconhecimento das influências exercidas por diferentes condicionantes ambientais sobre a estrutura e organização dos sistemas produtivos, assim como pela análise histórica das estratégias de desenvolvimento e subsistência empreendidas em escala local/regional. No caso da América Latina, onde é registrada significativa diversificação do ambiente, a observância das características locais/regionais torna-se mais crítica. Não obstante, os sistemas de produção florestal apresentarem características estruturais e de manejo semelhantes, os reflexos sobre o ambiente circunvizinho e a dinâmica sócio-econômica ocorrem de maneira diferenciada.

Fator de particular importância refere-se à biodiversidade instalada ou preexistente em determinada região ora ocupada por empreendimentos florestais. Regiões de climas temperados apresentam diversidade mais reduzida quando comparadas a zonas tropicais. Empresas florestais instaladas em tais regiões tendem a proceder ao manejo de áreas mais extensas, assumindo estratégia mista - exploratória/extrativista.

Dois fatores fundamentam a adoção desta estratégia:

- menor produtividade, induzida por fatores climáticos e resultantes biofísicas, estabelece a necessidade de áreas mais extensas para sustentação da atividade produtiva; 
- menor diversidade da cobertura florestal introduz parâmetros estruturais que propiciam o estabelecimento de planos de manejo e exploração com base em espécies endógenas ou exóticas.

Por serem áreas normalmente de menor densidade demográfica, os reflexos sobre a estrutura social são menos extensos, à exceção do deslocamento de comunidades indígenas e da inserção de pólos migratórios regionais. A exploração de recursos florestais endógenos e/ou introduzidos nestas regiões apresenta-se como alternativa econômica viável, frente à baixa disponibilidade de oportunidades - menor potencial de diversificação do setor primário.

Em função do menor índice de biodiversidade, os conceitos de manejo ambiental conservacionistas assumem características próprias, favorecendo, de certa forma, a manutenção de áreas mais extensas para exploração de florestas homogêneas. Atenção maior é conferida aos aspectos funcionais do ambiente, visto a estrutura não sofrer mudanças acentuadas em suas condicionantes originais.

Florestas em regiões tropicais, ao contrário, são pouco propícias ao estabelecimento de atividades extrativistas extensivas. A exploração florestal/industrial exige redução significativa da diversidade biológica, muitas vezes alcançada através da inserção de espécies exógenas de crescimento rápido. Este procedimento é em parte condicionado pela necessidade de manutenção de níveis adequados de produtividade e homogeneidade qualitativa dos produtos florestais para fins industriais.

Os reflexos ambientais observados a partir da inserção de florestas homogêneas consistem, basicamente, no decréscimo da biodiversidade local e na disruptura de alguns processos funcionais, sobretudo hidrológicos e de balanço de massas. Em função da maior concentração de recursos e meios de produção em um único setor produtivo, observa-se, ainda, mudanças desfavoráveis em alguns indicadores sócio-econômicos, em especial quanto a concentração fundiária e demais meios de produção.

A análise das implicações sociais e ambientais do desenvolvimento do setor florestal na América Latina deve considerar, todavia, processos históricos de colonização e exploração dos recursos naturais, assim como o contexto cultural e sócio-econômico nos quais estão atualmente inseridos. A importância desta avaliação é exemplificada pela análise comparativa entre diferentes zonas de produção florestal na América Latina. A área correspondente ao maciço florestal atlântico (Mata Atlântica), por exemplo, sofreu pressões extrativistas/exploratórias desde os primórdios da colonização. Os reflexos atuais correspondem à disponibilidade crescente de áreas degradadas e à maior concentração demográfica quando comparados aos índices observados nas regiões amazônica, interiores e de climas temperados. A atenção a tais fatores remete ao estabelecimento de estratégias de 
desenvolvimento distintas, dada a diferenciação das condições ambientais atualmente observadas e da demanda econômica e social dessas regiões. Assim, quaisquer análises ou prognósticos quanto à implantação e à operação do setor florestal/industrial na América Latina devem ser direcionados à comparação entre zonas similares.

As estratégias de exploração devem diferir de acordo com local/região considerados. Ecossistemas temperados, conforme observado, estão mais predispostos à exploração extensiva em função de características estruturais e funcionais intrínsecas desses ambientes. Apesar da baixa produtividade em termos comparativos, tais ambientes são geralmente reconhecidos como aptos ao estabelecimento de estratégias de manejo compatíveis com os níveis de demanda das indústrias de papel e celulose. As características estruturais de sistemas temperados não diferem de forma substantiva das florestas de produção, não sendo projetados impactos significativos pela introdução dos atuais procedimentos de manejo florestal nessas regiões.

Ambientes tropicais, ao contrário, apresentam condicionantes estruturais e funcionais distintos, merecendo atenção redobrada quanto à manutenção da biodiversidade para exploração sustentada dos recursos naturais. Em princípio, não parece recomendável a simples incorporação de tecnologias de manejo desenvolvidas em regiões temperadas, devendo ser estabelecidas estratégias de planejamento e operação distintas, as quais considerem fatores estruturais pregressos e características funcionais próprias de ambientes tropicais.

As diferenciações reconhecidas em escala local/regional permitem potencializar as possibilidades de exploração florestal a partir do reconhecimento de fatores limitantes e condicionantes primários do ambiente. O reconhecimento de tais características representam um primeiro passo rumo ao desenvolvimento sustentável, visto propiciar condições de ajuste das atividades produtivas segundo condicionantes previamente estabelecidas no ambiente.

\section{Impactos em escala global-planetária}

Outra questão correntemente relacionada a exploração de recursos florestais reporta-se às modificações observadas em escala planetária. Destas, a mais cogitada trata das mudanças climáticas, em especial quanto ao chamado efeitoestufa. O papel da conservação de grandes maciços florestais na manutenção dos climas globais permanece como elemento de intensas investigações. As primeiras indicações apontam para a importância destes ecossistemas na manutenção dos padrões climáticos em escala local/regional, apresentando, ainda, influência significativa nos padrões globais de circulação atmosférica. Todavia, muito resta a ser investigado para que possamos estabelecer inter-relações mais consistentes. Em especial, a questão da escala de diferentes fenômenos atmosféricos e sua 
relação com a cobertura vegetal permanece como incógnita em grande parte das investigações atualmente desenvolvidas.

Tema amplamente discutido refere-se à possibilidade de aprisionamento de parte das emissões antrópicas de $\mathrm{CO}^{2}$ a partir da implantação e manutenção de grandes maciços florestais. Esta questão é uma das que apresentam grande controvérsia na comunidade científica, visto restar uma série de aspectos a serem esclarecidos quanto ao ciclo de carbono em ecossistemas florestais. Ademais, como grande parte dos ecossistemas florestais com alta produtividade reporta uma taxa de produção/respiração muito próxima à unidade, a possibilidade de aumento do aprisionamento de carbono simplesmente pela manutenção de maciços florestais naturais parece improvável.

A implantação de florestas antrópicas para fins de aprisionamento de carbono merece atenção, embora apresente muitas incertezas quanto à viabilidade econômica de tais ações e a escala necessária para que sejam alcançados os efeitos desejados. Um estudo mais detalhado do ciclo de produção de papel e produtos correlatos pode elucidar algumas questões à medida em que torna possível o estabelecimento de períodos médios de aprisionamento. É necessário, neste caso, uma análise pormenorizada quanto a matriz energética empregada durante todo o ciclo de transformação, de forma a que seja possível constatar fontes secundárias de emissão de poluentes - em especial daqueles responsáveis pelo efeitoestufa.

\section{Avaliação do atual modelo de exploração florestal}

Grande parte dos sistemas de produção florestal estabelecidos na América Latina obedece a padrões estruturais e de manejo similares. São constituídos por plantações homogêneas, geralmente compostas por clones de espécies de crescimento rápido. Os procedimentos de manejo apresentam intensa entrada de energia, sendo diretamente dependentes da matriz energética clássica, a qual pressupõe alta disponibilidade de recursos para manutenção e exploração das florestas de produção. O sistema de exploração é intensivo, efetuando-se, geralmente, o corte raso em ciclos variáveis de 6 a 15 anos.

O modelo de produção florestal segue as assertivas estabelecidas pela revolução verde, tendo como referencial básico a maximização da produtividade imediata por área trabalhada. Muito embora o manejo florestal envolva períodos mais longos, as aspirações são essencialmente imediatistas, reportando-se ao planejamento estanque das atividades de manejo e ao reconhecimento da disponibilidade e manutenção dos recursos naturais necessários.

Os planos de manejo adotam, em sua maioria, uma abordagem reducionista quanto à questão ambiental, ficando restritos apenas aos aspectos silviculturais. 
A manutenção e a maximização da produtividade são definidas como elementos centrais destes modelos de produção florestal, sendo abordadas em segundo plano a qualidade ambiental, a estabilidade sócio-econômica e a preservação de bens culturais e antropológicos.

As abordagens a questões ambientais extrínsecas ao manejo florestal estão voltadas, em sua maior parte, ao atendimento de exigências estabelecidas por órgãos governamentais. Mais recentemente, com maior mobilização da opinião pública nacional e internacional em torno da conservação ambiental, as empresas do ramo florestal têm se deparado com crescentes pressões, muitas vezes refletidas em restrições de mercado. A análise e a avaliação das externalidades derivadas do processo produtivo estão voltadas, no entanto, quase que exclusivamente para a sustentação dos níveis de produção, apresentando como objetivo principal a manutenção da capacidade competitiva frente a diferentes mercados. Externalidades negativas do ponto de vista da sociedade local/regional não são comumente reconhecidas como de responsabilidade do setor produtivo, sendo transferidas para o âmbito governamental.

As limitações tecnológicas ao manejo de florestas de produção vêm sendo constantemente ultrapassadas, sem que sejam observados investimentos maciços em tecnologia. Preocupação maior tem sido conferida à etapa industrial do processo de produção, durante o qual são detectados riscos ambientais e operacionais mais imediatos. Exemplo deste posicionamento constitui a grande aceitabilidade e penetração do conceito de qualidade total nas etapas diretamente relacionadas ao ciclo de transformação, nas quais são internalizados normas e padrões reguladores do processo produtivo. A produção florestal assume como premissa básica, a manutenção de níveis adequados de qualidade e homogeneidade dos produtos florestais em atendimento aos processos de transformação. A qualidade e a perenidade do ambiente e dos recursos naturais são vistas como elementos acessórios e secundários dentro do ciclo de produção e transformação, muitas vezes considerados custos indiretos de produção.

A introdução de espécies exóticas, muito embora tenha despertado certa combatividade por parte de grupos ambientalistas, apresenta-se como solução imediata para o demanda industrial por produtos madeireiros. A constituição de florestas homogêneas, principalmente com base na biotecnologia (seleção genética e clonagem), tem permitido a redução relativa das áreas diretamente exploradas por meio do aumento da produtividade por área plantada e da qualidade e homogeneidade dos produtos florestais obtidos. A formação de florestas de produção derivadas do processo de seleção genética e clonagem tem se mostrado como tecnologia viável tanto em ambientes tropicais quanto em temperados.

Embora a substituição de sistemas de monocultivo por formações pluriespecíficas seja apresentada como proposta alternativa, esta parece, em 
princípio, tecnicamente inviável. As restrições observadas no processo produtivo são em grande parte resultantes das tecnologias florestais e industriais empregadas e do padrão de demanda (qualidade e características do produto) estabelecido pelo mercado. A complexidade envolvida na implementação e no manejo de tais sistemas resultaria em perda expressiva de competitividade, em particular por aumento dos custos e queda imediata da produtividade por área plantada. Devese considerar, ademais, os ganhos efetivos desta ação frente aos riscos impostos ao setor florestal e à sociedade a partir da retração do setor. Em princípio, projeta-se pequeno ganho relativo em biodiversidade quando comparado aos padrões de florestas nativas, não justificando a implementação imediata desta estratégia de manejo em programas conservacionistas ou de desenvolvimento sustentado.

Outra questão controversa trata do uso múltiplo das florestas de produção. Tais ações justificam-se desde que voltadas à diversificação das formas de utilização e à exploração de complexos florestais de produção. Na medida que a ênfase é dada simplesmente à maximização dos procedimentos de exploração de produtos florestais, sérios distúrbios funcionais podem ser ocasionados ao ambiente. As implicações mais óbvias indicam elevação imediata da demanda energética por meio da utilização intensiva de fertilizantes e defensivos agrícolas e aumento significativo da entropia global dos sistemas.

Os procedimentos de apropriação dos meios de produção florestal voltados ao atendimento de demanda industrial têm se mostrado como variável de caso a caso. Algumas empresas adotaram desde o início do empreendimento a concentração de todas as etapas da atividade produtiva, com a incorporação de grandes extensões de terras voltadas unicamente à produção de madeira. Outras assumiram estratégia mista, com a adoção de sistemas de parceria com produtores rurais, por meio de programas de fomento e contratos de compra e venda de produtos florestais.

Dois aspectos fundamentais são considerados para estabelecimento de diferentes modalidades de apropriação dos meios de produção, relacionados como:

- custo de oportunidade e disponibilidade efetiva de terras;

- minimização de risco do capital investido por meio da garantia de fornecimento de matéria-prima para as plantas industriais, sabidamente detentoras de grande parte do ativo imobilizado em empreendimentos de papel e celulose.

Programas de parceria são condicionados por capacidade de incorporação tecnológica, nível de capitalização e características culturais por parte dos produtores rurais. Como fator secundário, relaciona-se a infra-estrutura preexistente à implantação do empreendimento: a rede viária e demais fatores de suporte logístico imediato diretamente relacionados à atividade de exploração florestal. 


\section{Principais impactos sobre o meio ambiente}

A análise dos impactos ambientais de atividades florestais deve seguir a idéia já exposta: ambientes distintos estabelecem diferentes condições de contorno, apresentando graus variados de fragilidade e susceptibilidade a distúrbios naturais e antrópicos. A classificação quanto a amplitude e intensidade dos impactos mais freqüentes passa a ser uma função do contexto ambiental no qual se encontra implantado determinado empreendimento, bem como da escala de investigação.

Os principais impactos ambientais das atividades de exploração florestal, sobretudo de florestas implantadas, estão relacionados à redução da biodiversidade local/regional, às mudanças climáticas, às alteração dos ciclos hidrológicos, ao aumento da entropia dos sistemas de paisagem, às alterações nos fluxos de matéria e energia e aos reflexos sobre as estruturas sócio-econômica e cultural. Como elementos secundários são indicados impactos sobre o solo, riscos de contaminação ambiental e descaracterização estética da paisagem.

Os impactos mais expressivos sobre a biodiversidade são observados quando da substituição de florestas nativas por formações homogêneas. Permanecem incertos, todavia, os reflexos da redução da heterogeneidade estrutural em escala de paisagens sobre a biodiversidade, bem como o dimensionamento de áreas mínimas para preservação de parcela significativa da diversidade genética regional. Incertezas permanecem quanto à melhor estratégia de desenvolvimento de programas de preservação ambiental, cabendo a elucidação das mesmas para que propostas e ações preservacionistas implementadas atinjam os objetivos esperados.

A questão da biodiversidade é correntemente tratada como elemento exógeno ao processo produtivo, no qual são estabelecidas áreas de preservação e conservação sem que seja considerada de forma explícita sua relação com florestas de produção. A definição espacial das áreas de preservação segue orientação estabelecida pela legislação pertinente, a exemplo dos códigos florestais, nos quais são definidas áreas não passíveis de exploração. As áreas de preservação são delimitadas segundo preceitos legais sem que haja preocupação objetiva com a preservação do patrimônio genético das regiões sob influência dos empreendimentos florestais. A sistemática corrente corresponde à tentativa de maximização das áreas plantadas, tendo como referencial a oferta de matéria-prima para transformação industrial e a redução dos custos imediatos de produção.

Embora seja algumas vezes aventada a possibilidade de mudanças climáticas derivadas da implantação de florestas de produção, estas são consideradas como remotas frente à diferença em escala dos fenômenos de circulação atmosférica e à amplitude espacial das plantações, mesmo de extensos complexos homogêneos. Projetam-se alterações climáticas nas áreas de entorno dos 
empreendimentos florestais (efeito de borda) quando da substituição de coberturas não-florestais. Os principais reflexos relacionam-se à variação nas taxas de evapotranspiração e padrões de circulação local, com redução potencial da temperatura e aumento da precipitação pluviométrica. Efeitos mais óbvios são observados em nível microclimático.

Impacto mais relevante sobre o clima regional/global está relacionado à supressão de grandes extensões de florestas, em especial na região amazônica e em áreas alagadas. Este processo dá-se comumente pelo emprego de queimadas, durante as quais são emitidas grandes quantidades de poluentes primários responsáveis pelo efeito-estufa. A participação direta do setor florestal latino-americano como agente de tal processo é classificada atualmente como não-significativa. A inserção deste setor é observada de forma indireta por meio da matriz energética utilizada em cada caso.

Impactos sobre o ciclo hidrológico são indicados como os mais expressivos e preocupantes, em especial quando da introdução de espécies de crescimento rápido. $\mathrm{O}$ estado das artes quanto à hidrologia florestal não permite, no entanto, estabelecer relação conclusiva e genérica referente à demanda hídrica e ao comprometimento da disponibilidade de recursos em resposta à introdução dessas espécies florestais. Estudos realizados em ambientes tropicais apontam para taxas de demanda similares entre florestas de produção e nativas (Lima, 1994).

Calder et al. (1992), em pesquisas desenvolvidas na Índia, indicam resultados conflitantes quanto à inter-relação entre a disponibilidade local de recursos hídricos e a presença de florestas de produção (formações compostas por clones do gênero Eucalyptus). Avaliações fisiológicas de espécies e clones mais utilizados apontam para taxas de evapotranspiração (demanda hídrica) iguais ou inferiores às de algumas espécies nativas de florestas tropicais.

Muito resta a ser feito em pesquisas básicas para que se possa estabelecer de forma conclusiva qual o impacto da substituição de florestas naturais por formações homogêneas de crescimento rápido sobre o ciclo hidrológico em escalas local/regional. Parece claro, no entanto, a impossibilidade de serem estabelecidos padrões genéricos de funcionamento, sendo mais pertinente a consideração das particularidades intrínsecas a cada região.

Não obstante, observa-se a ausência de esforços objetivos para a implementação de programas específicos de gerenciamento desta classe de recurso. Ao contrário do solo, que tem merecido crescente atenção por parte das equipes de pesquisa e manejo de empresas do setor florestal, os recursos hídricos são relegados às incertezas inerentes aos sistemas naturais. Os esforços e ações de manejo estão voltados para garantir o provimento de recursos destinados a atividades específicas, como abastecimento industrial e de viveiros, não sendo externada 
preocupação quanto ao dimensionamento e investigação da dinâmica espaçotemporal de estoques hídricos.

A exemplo da questão da biodiversidade, a abordagem dos recursos hídricos segue prerrogativas legais estabelecidas quando do licenciamento ambiental dos projetos. Nestas são adotadas como normas de manejo níveis máximos aceitáveis de contaminação de lençol superficial por efluentes industriais e distanciamento médio das formações florestais a partir da margem de corpos d'água superficiais.

Impactos sobre a estrutura e dinâmica sócio-econômicas estão diretamente relacionados à apropriação extensiva dos meios de produção, em particular concentração fundiária e modificações nas relações de capital-trabalho. Apesar das aquisições de terra constituírem negociação entre as partes envolvidas, a concentração fundiária tem relevante potencial de geração de conflitos. As modificações da relação capital-trabalho são verificadas a partir do surgimento do sindicato de trabalhadores rurais e da extensão, ao meio rural, de benefícios trabalhistas. Ademais, observa-se a inserção de novos agentes sociais, a exemplo de agremiações religiosas e político-partidárias, aumentando os níveis de complexidade nos processos de negociação. À medida em que as ações de negociação tornam-se cada vez mais raras, o processo de interação radicaliza-se, projetandose perdas consideráveis em produtividade e qualidade de vida das populações em escala local/regional caso tal tendência não seja revertida.

O fator escala constitui, adicionalmente, elemento de extrema importância na avaliação e relativização dos impactos ambientais. A intensidade e importância relativa de determinada técnica de manejo sobre a estabilidade de processos funcionais resulta, em parte, da escala de abordagem. Sistemas espacialmente mais abrangentes tendem, em princípio, a exercer impactos mais significativos. Todavia, a avaliação desses impactos está diretamente relacionada à escala dos fenômenos analisados.

Da mesma forma, a implementação de processos de desenvolvimento sustentável deve ser avaliada segundo a escala analítica dos processos correlacionados. Os reflexos desta abordagem tornam-se mais evidentes quando adotados os conceitos de manejo de paisagens, bacias hidrográficas ou outra unidade físicoambiental/administrativa. A dinâmica dos impactos observados em escala de microbacia, por exemplo, difere daquelas reconhecidas para bacias hidrográficas, demandando ações de manejo específicas.

\section{Estrutura organizacional e meio ambiente}

Programas de qualidade total e re-engenharia de processos têm alcançado grande aceitabilidade e sucesso relativo na redução dos custos globais de produção e melhoria qualitativa dos produtos a partir da implementação de mudanças 
na estrutura organizacional das empresas. Igual paralelo pode ser projetado quanto aos reflexos desses programas na administração de processos ambientais. Embora mais refratário a mudanças conceituais e operacionais, o setor florestal das empresas de papel e celulose tem apresentado resultados positivos frente à implementação de tais programas. A meta consiste no estabelecimento de estruturas mais horizontalizadas e integradas, nas quais processos são administrados, não ocorrendo a distribuição clássica de atributos e responsabilidades de forma compartimentada.

A premissa básica para se alcançar sucesso em programas de desenvolvimento sustentado fundamenta-se nos mesmos conceitos de gerenciamento. Mudanças organizacionais devem ocorrer, agora, em sentido oposto, levando para fora dos limites do empreendimento o conceito de negociação e re-engenharia de processos. Neste caso, torna-se necessária a horizontalização das relações entre empresas e sociedade, com a partilha de responsabilidades e distribuição de benefícios advindos do desenvolvimento regional.

Projeta-se que grande parte das dificuldades na implementação de programas de desenvolvimento sustentável serão encontradas, em primeira instância, na própria estrutura de determinadas empresas e setores, a exemplo do setor florestal. Por agregar processos com alto grau de incerteza e progressão tecnológica mais difusa, o setor florestal de empresas de papel e celulose tende a apresentar comportamento mais conservador.

Ademais, como as economias latino-americanas apresentam, historicamente, um nível de intervenção governamental elevado, as empresas desenvolveram ao longo de sua existência uma postura relativamente isolacionista quanto a administração de determinados processos - em especial quanto à negociação direta com a sociedade. Os procedimentos de interfaceamento eram, em sua maioria, realizados entre empresas e governo, relegando a segundo plano a interação direta com as comunidades locais/regionais. Tal procedimento conduziu à rela$c ̧ \tilde{a} o$ de mudos, na qual as partes envolvidas não reconhecem inteiramente a legitimidade e atuação dos diversos agentes produtivos e sociais.

As mudanças nas economias regionais e global têm implicado, todavia, necessidade de maior agilidade e flexibilidade na administração de processos produtivos e na resolução de conflitos. Tal posicionamento exige um nível de interação mais maduro e efetivo entre as partes envolvidas, de forma a evitar impasses que resultem em entraves ao processo de desenvolvimento. À medida em que os investimentos realizados no setor florestal são comparativamente menores frente às unidades industriais de processamento e transformação, isto permite a redução dos riscos quanto à introdução de mudanças mais significativas nas formas de operação e interação com a sociedade. Parece um paradoxo, mas talvez o setor considerado como o mais conservador do empreendimento represente o 
agente mais propício à introdução de conceitos mais avançados quanto ao desenvolvimento sustentável.

\section{Medidas acauteladoras}

Medidas intermediárias podem ser, e em parte estão sendo, adotadas para minimizar alguns impactos ambientais negativos. Investimentos em prevenção de processos de contaminação físico-química, comprometimento qualitativo dos recursos hídricos e atmosféricos, contenção de processos erosivos e de perda de solos e preservação de ecossistemas ameaçados constituem exemplos. A adoção do plantio direto por parte de algumas empresas, assim como o desenvolvimento do conceito de sítios ambientais, representam ações que procuram adequar as atividades de produção florestal a condicionantes previamente reconhecidas no ambiente. Estudos de balanço de massas, em particular quanto ao ciclo biogeoquímico de alguns nutrientes de maior demanda e a demanda hídrica, são igualmente desejáveis.

Programas de educação ambiental constituem outro exemplo positivo. Uma série de conceitos é abordado durante a execução de tais programas, muitas vezes com o envolvimento de comunidades locais. Estes atuam como instrumentos de difusão de novas perspectivas de avaliação do conceito de ambiente enquanto elemento integrante do empreendimento, colaborando no desenvolvimento de nova mentalidade entre funcionários e sociedade local/regional. Ademais, funcionam como agente de interface entre empresa e sociedade, permitindo o estabelecimento de espaço comum não-convencional para interação direta dos diversos agentes e elementos representativos em nível local/regional. Deve-se, no entanto, estender a ação desses programas além de aspectos puramente teóricos ou propagandísticos, estabelecendo-se bases concretas para a mudança comportamental da relação entre empresas e representantes locais/ regionais e demais agentes sociais.

Maior preocupação advém do fato de grande parte das ações consideradas conservacionistas e de redução de impactos estar sendo adotada de maneira formal e sobretudo empírica. As atividades relacionadas ao ambiente extraflorestal são consideradas estranhas ao processo produtivo. Segue-se o paradigma clássico do ambiente como reservatório de recursos naturais, muitas vezes considerados inesgotáveis.

As empresas do setor florestal resumem sua atuação ambiental, em grande parte, ao atendimento de condicionantes legais, quase nunca ultrapassando os limites estabelecidos por agências governamentais de proteção ambiental. $\mathrm{O}$ atendimento a padrões estabelecidos pelo mercado é geralmente direcionado à etapa de transformação industrial, cabendo ao setor florestal atender a questionamentos, no geral pouco objetivos e fundamentados. 
Com o surgimento de novos agentes sociais representativos, como as organizações não-governamentais, as empresas têm se defrontado com novas e constantes exigências e questionamentos, sobretudo quanto a questões de cunho social e político. Todavia, a reação observada assume, geralmente, caráter isolado, cada caso sendo tratado separadamente. Ao que parece, não existe política ambiental consistente por parte do setor produtivo.

\section{Fatores de sustentabilidade do setor florestal}

O estabelecimento de estratégias de desenvolvimento sustentável para o setor de papel e celulose envolve mudança conceitual na acepção dos empreendimentos, na sua relação espaço/temporal e na gestão coerente das externalidades positivas e negativas. Novas propostas devem estar aptas a lidar de forma objetiva com questões tão diversas quanto a biodiversidade, o desenvolvimento sócioeconômico regional e a qualidade ambiental.

Tais modelos apresentam estrutura mais flexível, sendo passíveis de ajustes e correções, de acordo com as variações intrínsecas e extrínsecas ao empreendimento. A sobrevivência do setor florestal na América Latina está, cada vez mais, relacionada com o potencial de adaptação a diferentes contextos, expresso pela capacidade de negociação com os diferentes agentes sociais envolvidos nos cenários internos.

À medida em que um dos fundamentos do conceito de desenvolvimento sustentável é a gestão de recursos naturais, o estabelecimento dos níveis econômico e socialmente viáveis passam a ser definidos por fatores limitantes e balizadores intrínsecos do ambiente. Características físicas (abióticas) são genericamente consideradas como elementos que definem de forma imediata a capacidade de suporte de determinado local. Em contraposição, condicionantes sócioeconômicos estabelecem o nível de tolerância às externalidades negativas geradas pelo setor produtivo. É fundamental compatibilizar a viabilidade técnica do setor florestal com o desenvolvimento sócio-econômico regional.

A probabilidade de sucesso de determinado empreendimento resulta da combinação de características intrínsecas do ambiente, ora denominadas condições de estado primitivas, e dos meios tecnológicos empregados na alocação específica destes recursos. Este conceito diferencia-se da definição clássica de aptidão agrícola e/ou florestal, visto ser necessário incorporar a dimensão temporal para que sejam alcançados níveis de sustentabilidade em intervalos mais longos. Assim, um local/região apresenta determinado nível de aptidão ao desenvolvimento de uma atividade produtiva/exploratória na medida que conjuga fatores específicos, tais como solos, clima, relevo e recursos hídricos. Os níveis de sustentabilidade são definidos por estratégia de manejo que compatibilize a utilização dos recursos com a manutenção da integridade de mecanismos de auto- 
regulação (feedback) dos sistemas ambientais e da qualidade de vida das populações afetadas.

A possibilidade de serem estabelecidos sistemas produtivos sustentáveis por longos períodos é condicionada por processos funcionais do ambiente em sua acepção mais ampla, na qual são objetivamente considerados fatores direta e indiretamente relacionados à atividade florestal. $\mathrm{O}$ suprimento da demanda de madeira para uma planta industrial não está mais circunscrito apenas à extração de madeira em determinado intervalo espaço-temporal, mas também à compatibilização desta atividade setorial em um contexto que considere fatores extrínsecos ao manejo florestal. O gerenciamento de recursos hídricos por meio do manejo de bacias hidrográficas é citado como exemplo. A viabilidade operacional de diferentes setores e atividades produtivas é uma função da possibilidade de compatibilizar interesses e objetivos distintos, dinamicamente relacionados em um mesmo intervalo espacial - a bacia hidrográfica. Na medida que determinadas atividades, a exemplo de exploração florestal ou produção industrial, implicam interferência ou competição pelo uso de determinados recursos, como exploração pesqueira ou agricultura irrigada, a sustentabilidade ambiental de tais empreendimentos passa a ser conceitual e operacionalmente questionada.

A implementação do conceito de desenvolvimento sustentado pelo setor florestal passa, ademais, por aspectos mais restritos ao manejo florestal. Determinadas estratégias de manejo de recursos podem representar fatores restritivos à própria atividade fim. A incorporação de nutrientes por intermédio do aproveitamento de resíduos de colheitas, bem como a proteção dos recursos hídricos e edáficos por técnicas conservacionistas, proporcionam maior sustentabilidade à atividade exploratória, na medida que processos funcionais intrínsecos ao ambiente são incorporados às técnicas de manejo. Outro exemplo trata do reconhecimento de sítios florestais, conceito de site, onde fatores aparentemente extrínsecos, como proximidade a reservas naturais, constituem elementos balizadores do sucesso, expressos inclusive pela estabilidade dos níveis de produção.

A diferenciação conceitual de um novo modelo de exploração florestal reporta-se, assim, à incorporação explícita de valores e prerrogativas ambientais aos procedimentos de manejo da base de recursos naturais. Neste caso, passa-se a tratar de manejo ambiental, dentro do qual insere-se, inclusive, a manutenção de florestas de produção. Inverte-se a sistemática atual, na qual a floresta é considerada como elemento extrínseco ao ambiente. Esta passa a ser operacionalmente inserida em um contexto mais amplo, no qual a produção de madeira constitui um dos elementos de gerenciamento e gestão do ambiente.

A extensão do conceito de ambiente propicia elementos teóricooperacionais para a abordagem de desafios atualmente contrapostos ao desenvolvimento econômico. Permite a manutenção da biodiversidade e qualidade 
ambiental, os níveis de produtividade e a atenção às necessidades de sustentação de sociedades regionais. A conservação ambiental, em particular preservação da biodiversidade, é tratada em escala não apenas pontual, mas por meio da conjugação dos diferentes elementos - ecossistemas - componentes de um ambiente. Tal abordagem possibilita inserir de forma objetiva aspectos anteriormente relegados a segundo plano, em especial aqueles relacionados à funcionalidade e à interdependência de processos e componentes estruturais do ambiente.

O papel do reordenamento espacial de paisagens no desenvolvimento sustentado representa a diluição, no espaço e no tempo, das diversas externalidades geradas por atividades e interesses setoriais. Sistemas heterogêneos permitem o estabelecimento de bases mais estáveis de produção e desenvolvimento, na medida que possibilitam a coexistência de diferentes prerrogativas produtivas e preservacionistas em um mesmo espaço e a conjugação de diferentes estratégias de desenvolvimento na dimensão temporal. A adoção de um sistema descentralizado de produção florestal permite, por exemplo, a atenuação dos conflitos sociais gerados pela excessiva concentração fundiária inerente a alguns modelos de exploração. O incentivo a programas de fomento e parceria com pequenos e médios produtores rurais exemplifica tal estratégia de ação. Representa a possibilidade de capitalização do setor primário por intermédio da diversificação de sua base de produção, com a melhoria da distribuição de renda em escala regional.

Sem incorrer em ações assistencialistas, as empresas florestais passam a exercer papel fundamental no alavancamento do processo de desenvolvimento regional, não sendo verificado aumento significativo dos riscos inerentes ao processo produtivo. Projeta-se o aumento da sustentabilidade do setor, na medida que o ambiente torna-se mais apto à incorporação de inovações tecnológicas e de manejo a custos relativamente menores. Ocorre a diluição de responsabilidades e atribuições, concomitantemente à redistribuição mais eqüitativa dos benefícios e externalidades geradas pelo processo de desenvolvimento regional.

A gestão de um novo modelo de produção florestal pode ser resumida como a internalização de conceitos ambientais mais amplos no gerenciamento de uma atividade específica - setor florestal. A produção de matéria-prima para abastecimento industrial passa a ser integrada em um plano de gestão ambiental que considere de forma objetiva as prerrogativas de desenvolvimento multissetorial e a preservação de patrimônio ambiental e cultural inerentes a determinado local e/ou região.

O gerenciamento de externalidades possibilita a integração do setor florestal em um processo mais amplo de desenvolvimento sustentável, contemplando tanto a manutenção dos ciclos produtivos e de mercados quanto a melhoria das condições gerais de vida das populações. No caso específico da América Latina, o fator sociológico assume especial importância, visto parcela significativa 
da sociedade não participar ativamente do processo de desenvolvimento econômico regional.

\section{Estratégias de implementação}

\section{Conceituação}

A adoção de uma sistemática de sustentabilidade do desenvolvimento econômico e social requer o estabelecimento de estratégias de transição voltadas à transposição, a menos traumática possível, do modelo atual para o sistema de gerenciamento pretendido. Os fatores que balizam tal ação estão relacionados ao reconhecimento das condições de estado do ambiente, de táticas específicas conforme análise de riscos ambientais/econômico-financeiros e treinamento/ conscientização dos agentes sociais diretamente participantes. A disposição política constitui pedra fundamental do processo e deve ser orientada por procedimentos transparentes de negociação entre os diversos agentes sociais e representantes de interesses setoriais específicos.

À semelhança do estabelecido em programas de qualidade total e re-engenharia de processos, a meta não constitui a substituição de um sistema estanque por outro. Ao contrário, representa mudança, em especial cultural, na administração dos processos envolvidos. Passa-se a trabalhar através do reconhecimento de desconformidades e da implementação de procedimentos de ajuste de forma dinâmica, na qual o papel dos sistemas de retroalimentação são fundamentais para que sejam alcançados níveis aceitáveis de qualidade e estabilidade do processo produtivo. De forma similar aos sistemas de auto-regulação de fenômenos naturais, o conceito de cibernética induz ao estabelecimento de uma nova dinâmica de gerenciamento, baseada e resultante de processos e mecanismos de retroalimentação - feedbacks.

De forma resumida, elencam-se as etapas de planejamento e gerenciamento como instrumentos básicos em programas de gestão ambiental e desenvolvimento sustentado. O planejamento estratégico, elaborado de acordo com diagnósticos e prognósticos florestais/ambientais, define direção e sistemática a serem seguidas na operacionalização de processos de transição para o desenvolvimento sustentável. Ao gerenciamento ambiental cabe a manutenção e o ajuste dos sistemas de manejo implementados, utilizando as ferramentas de monitoramento para acompanhar fenômenos e processos relevantes às atividades de exploração florestal para fins industriais.

\section{Instrumentos de planejamento e gerenciamento ambiental}

O primeiro passo refere-se ao reconhecimento detalhado dos fatores diretamente relacionados ao processo a ser gerenciado e aos níveis de inter-relação 
existentes. No caso de sistemas ambientais, deve-se considerar, em especial, a dinâmica espaço-temporal de determinados fenômenos, bem como o grau de incerteza inerente aos níveis de conhecimento científico-tecnológico atuais. A gestão de sistemas com alto índice de incerteza exige a adoção de estratégia mais prudente, na qual as condições de contorno estabelecidas para gerenciamento comportem maior margem de segurança; como no caso do dimensionamento da carga máxima de uma barragem, o qual é estreitamente dependente dos padrões de escoamento e vazão de determinada bacia. Caso não se disponha de informações que permitam o estabelecimento de simulações precisas da dinâmica hidrológica da região em questão, adota-se o superdimensionamento das estruturas como elemento de compensação. Idêntica relação deve ser estabelecida quanto ao manejo de sistemas ambientais de alta complexidade.

O reconhecimento das relações espaciais entre os diversos elementos de uma paisagem pode ser considerado como a primeira internalidade a ser objetivamente analisada. Tais relações são inicialmente circunstanciadas pela elaboração de zoneamentos ambientais, em especial daqueles denominados ecológicoeconômicos. Este instrumento analítico permite estabelecer ao grupo de gestão uma visão sinóptica das potencialidades de um sistema ambiente e o reconhecimento das inter-relações entre os diversos componentes de uma paisagem. Tais informações são de fundamental importância quando consideradas a inserção e a interação de diferentes setores e processos produtivos dentro de uma mesma unidade geoambiental.

Este procedimento pode ser adotado em diferentes escalas espaço-temporais. Projeta-se o zoneamento de uma bacia hidrográfica ou microrregião administrativa da mesma forma como é efetuada a compartimentação por unidades geoambientais em locais direcionados ao uso por florestas de produção. Em ambos os casos são previamente estabelecidos e consensados normas e princípios que permitem a compartimentação ambiental em zonas homogêneas. Exemplo desta metodologia, ressalvadas as particularidades, trata do mapeamento da cobertura pedológica de uma região, no qual são considerados inúmeros atributos e parâmetros para classificação e reconhecimento espacial de unidades homogêneas.

O estabelecimento de uma relação entre padrões estruturais de paisagens e processos funcionais - mais afeitos às estratégias de manejo - permite a simulação do comportamento dinâmico de determinado componente frente à adoção de novas tecnologias de manejo. É possível projetar o comportamento provável de determinada classe de recursos, por exemplo, hídricos, frente à implantação, à expansão ou ao redirecionamento de sistemas de manejo de florestas de produção. Por meio desses prognósticos detecta-se previamente possíveis conflitos de interesses, permitindo a proposição de estratégias alternativas de gerenciamento e exploração. 
A análise de processos históricos de uso/ocupação de determinada região, bem como a evolução na adoção de diferentes tecnologias de manejo florestal e ambiental, permite o estabelecimento de diagnósticos ambientais. A partir destes, são definidas estratégias de ação que contemplem intervenções de curto, médio e longo prazos.

A inserção de conceitos ambientais ao planejamento estratégico de atividades de exploração florestal está intimamente relacionada à disponibilidade de informações que permitam o reconhecimento imediato das condições de estado dos sistemas manejados (diagnósticos ambientais), bem como à projeção dinâmica dos fenômenos mais relevantes (prognósticos). A seguir, são elaboradas e detalhadas ações específicas de manejo, voltadas à correção e otimização dos processos produtivos, de forma a torná-los mais sustentáveis.

\section{Regulamentação de uso de recursos comuns à sociedade}

A regulamentação crescente do uso dos recursos hídricos por parte de alguns países externa a criticidade no estabelecimento de sistemáticas integradas de exploração dos recursos naturais. Recurso inicialmente concebido como inesgotável, passa a apresentar-se como limitante em função do aumento de conflitos na utilização múltipla por parte de diferentes setores. Ademais, práticas indevidas têm induzido a aumento extremo dos custos de manejo quando se faz necessária a adoção de medidas corretivas dos processos de degradação ou de redução significativa da disponibilidade efetiva do recurso.

A utilização de práticas conservacionistas no manejo de solos segue as mesmas prerrogativas. Práticas ótimas de manejo (best management practices) permitem o estabelecimento de normas voltadas à conservação dos recursos edáficos, externadas sobretudo pela restrição à ocorrência de processos de erosão e assoreamento. Estendem-se além das práticas de manejo florestal, normalizando a implantação e a manutenção da rede viária interna das áreas florestadas e demais processos que impliquem desestabilização do compartimento edáfico.

Outro aspecto favorável quanto à utilização de técnicas conservacionistas concerne à possibilidade de maior controle sobre a migração de nutrientes e demais agroquímicos utilizados no manejo florestal. Quando carreados, juntamente com sedimentos ou em suspensão, tais elementos contribuem para a eutrofização e a contaminação dos corpos d'água, impingindo impactos negativos sobre a disponibilidade e qualidade dos recursos hídricos superficiais e subsuperficiais.

\section{Monitoramento ambiental}

O estabelecimento de sistemas de monitoramento ambiental favorece 
igualmente o controle dos processos envolvidos em atividades de exploração florestal. Estas técnicas podem ser classificadas de acordo com os fenômenos observados ou ainda por estarem focadas em estrutura ou funcionamento do ambiente. Técnicas de monitoramento estrutural estão relacionadas à observação das variações espaciais da cobertura florestal, à qualidade das águas e ao controle atmosférico.

A análise destes dados, utilizando-se técnicas de modelagem matemática, permite a simulação dos possíveis cenários advindos de determinada modificação estrutural do ambiente - projetada dentro do programa de manejo ou por eventos catastróficos. O planejamento de exploração florestal em determinada área de uma microbacia ou bacia hidrográfica, com retirada de parte da cobertura vegetal, permite ao setor de gerenciamento ambiental antever o aumento da carga de escoamento dos tributários e rios principais, bem como as possíveis variações quanto à qualidade da água. Outra aplicação trata da avaliação do balanço de massas relativo à utilização de fertilizantes. A partir da caracterização de parâmetros-chave, tais como recobrimento do solo e taxas de fertilização, é possível avaliar as taxas de transporte e fixação de nutrientes nas parcelas manejadas, antevendo-se possíveis reflexos sobre os demais elementos componentes da paisagem (ou bacia hidrográfica), bem como a própria eficácia das técnicas empregadas frente aos resultados projetados e alcançados.

O monitoramento de parâmetros hidrológicos, inclusive meteorológicos, aliado à avaliação de características estruturais dos solos e lençol subsuperficial, permite estabelecer um programa de gerenciamento de recursos hídricos. A avaliação criteriosa da disponibilidade e qualidade dos recursos, ademais do favorecimento na resolução de conflitos de uso múltiplo, permite um manejo sustentado das atividades florestais. Como um dos fatores essenciais ao estabelecimento de taxas ótimas de produção florestal, estes representam um dos elementos básicos de monitoramento em planos de gestão ambiental. A utilização de modelos agrometeorológicos, por outro lado, permite estabelecer sistemas de previsão de safras, nos quais estão inclusas projeções de mobilização de recursos naturais por parte de florestas de produção.

Alguns parâmetros funcionais são igualmente úteis para a avaliação da eficácia dos programas de gestão e transição para o desenvolvimento sustentado. $\mathrm{O}$ reconhecimento de bioindicadores apresenta-se como uma das técnicas passíveis de utilização. Pelo acompanhamento da dinâmica populacional - expressa muitas vezes pela abundância ou freqüência relativas de determinadas espécies - é possível estimar o grau de estabilidade de um sistema ambiente. Ao contrário, o surgimento de espécies oportunistas é geralmente considerado como um indicativo de estresse ambiental. Índices de respiração edáfica, assim como taxas de decomposição de folhedo, são igualmente utilizados para a avaliação da estabilidade ou do estresse de determinado ambiente. 
Parâmetros sócio-econômicos constituem elementos de monitoramento que permitem identificar as externalidades intrínsecas ao manejo de florestas de produção. Indicadores demográficos, econômicos e sociais possibilitam a detecção e acompanhamento de conflitos e desconformidades derivados da implantação e manutenção de complexos florestais/industriais. As informações obtidas através do monitoramento sócio-econômico possibilitam a inserção das dimensões sociais e culturais no planejamento e gerenciamento de programas de desenvolvimento sustentável. Na medida em que uma das prerrogativas da sustentabilidade trata especificamente da qualidade de vida das populações locais/regionais, métodos de monitoramento sócio-econômicos constituem instrumentos essenciais para a avaliação e acompanhamento de processos de transição para o desenvolvimento sustentável no setor florestal.

\section{Acompanbamento em nível macroambiental}

O sucesso na implementação de programas de desenvolvimento sustentável está diretamente relacionado à gestão dos diversos processos envolvidos. Cabe, neste caso, o estabelecimento de ferramentas analítico-operacionais que permitam o acompanhamento e diagnóstico dos programas de transição e gestão. Instrumentos como auditorias ambientais - internas e externas - e programas de conscientização (educação ambiental) são exemplos já testados em outros contextos e que alcançaram relativo sucesso.

A exemplo de programas de qualidade total, o sucesso da implementação de procedimentos de gestão ambiental está relacionado ao grau de comprometimento de cada um dos agentes envolvidos no gerenciamento do processo produtivo. A recente proposição de um certificado de qualidade ambiental - ISO 14.000 - pode representar a inserção de tais instrumentos nos procedimentos de gestão de programas de desenvolvimento sustentável. Certificados outros, como o selo verde, podem, igualmente, ser capitalizados para a melhoria dos processos produtivos. Cabe, entretanto, uma discussão mais ampla quanto à adequacidade dos referenciais técnicos estabelecidos. É necessário, conforme já discutido, considerar as peculiaridades de cada região analisada, não parecendo coerente, em primeira instância, o estabelecimento de regras genéricas. A simples transposição de valores estabelecidos como referenciais para outras regiões, a exemplo de Europa e América do Norte, pode resultar em efeito contrário ao esperado. Ao invés de incentivar a implantação de programas de desenvolvimento sustentável, tais valores serviriam apenas como barreiras não-tarifárias, restringindo a abordagem da proposta original de sustentabilidade em nível global.

Uma série de incentivos à adoção de programas de desenvolvimento sustentável por parte do setor florestal latino-americano pode ser estabelecida. A diferenciação de um produto com base na qualidade ambiental e em seu processo 
de transformação pode ser refletida pelo diferencial no posicionamento relativo no mercado internacional. Tais incentivos são definidos, por exemplo, por meio de redução de impostos diretos ou de tratamento diferenciado.

\section{Contextualização política}

Os principais desafios à adoção de uma estratégia de desenvolvimento sustentado estão relacionados, em primeira instância, a aspectos políticos e conceituais. A mudança no atual posicionamento político quanto ao desenvolvimento econômico e social, e sua associação com a crise ambiental emergente, representa força propulsora para futuros desenvolvimentos técnico-científicos. Todavia, o aparato científico-tecnológico não está capacitado a definir sozinho os direcionamentos necessários à adoção de um programa genérico ou setorizado de desenvolvimento sustentável.

A resolução de questões colocadas como eminentemente técnicas, tais como impactos ambientais no âmbito regional, globalização econômica e de interesses setoriais, dentre outras, está vinculada, em primeira instância, ao posicionamento político dos diversos segmentos da sociedade. Esperar mudanças do consciente coletivo para que os aprimoramentos necessários se façam presentes é impossível frente à premência e à incerteza quanto aos aspectos temporais de fenômenos emergentes. Resta aos formadores de opinião, oriundos dos mais diversos setores - governamentais, civis, científicos ou empresariais -, a predisposição ao estabelecimento de bases consistentes de negociação, com a proposição de ações concretas e de sistemática de interação intensiva.

A manutenção de alguns paradigmas é incompatível com o estabelecimento de nova sistemática de manutenção e desenvolvimento das sociedades modernas. É difícil imaginar a sustentabilidade físico-orgânica da sociedade mantendose como padrões as atuais referências de demanda por bens e serviços. A transposição dos padrões de consumo de sociedades desenvolvidas para países em desenvolvimento é fisicamente impossível. Por outro lado, a manutenção dos atuais níveis de desigualdade social tem implicado distorções de difícil sustentação, com conseqüências imprevisíveis quanto à estabilidade e perenidade dos atuais sistemas de organização social e política.

A ruptura de paradigmas resulta da adoção de estratégias não-imediatistas e implementação de ações integradas de desenvolvimento, com os interesses setoriais tratados dentro de uma perspectiva mais ampla de sustentabilidade de toda a sociedade. A premência por mudanças concretas e emergenciais remete à articulação de estratégias orientadas por posicionamento político, sustentado por disposições sociais e científicas arregimentadas para um mesmo fim: sobrevivência da sociedade humana sobre fundamentos de maior sustentabilidade. 
O instrumento de gestão ambiental insere, neste contexto, conceito semelhante à re-engenharia dos processos de produção. A abordagem pretendida, de caráter matricial, tende a integrar as diversas atividades do setor florestal em procedimentos de gerenciamento de processos. Neste caso, os processos são representados não somente pelo sistema produtivo em sua acepção mais restrita, como também por fenômenos ou processos ambientais relacionados. O setor florestal assume postura não apenas de consumidor mas também de gestor ambiental, em particular quanto às externalidades derivadas do uso dos recursos naturais. À medida em que outras atividades relacionadas ao processo produtivo dependem da utilização intensiva de determinado recurso, novas perspectivas são adicionadas ao processo de gestão. Administra-se, por exemplo, o ciclo ou balanço hidrológico em escala regional, atendo-se não somente ao suprimento da demanda imediata e setorial, mas à administração temporal e interativa do recurso. A adoção de procedimentos de co-responsabilidade por parte de setores representativos da sociedade constitui fator imperativo ao sucesso de programas de desenvolvimento sustentado.

As externalidades positivas e negativas devem ser negociadas em fórum mais amplo, de forma a adequar os níveis de disposição espaço-temporal à capacidade de absorção e mudanças das sociedades afetadas. Na medida que estes não são considerados como sistemas fechados, as externalidades geradas pelo setor florestal são sentidas em diversos segmentos da sociedade, ocasionando, por outro lado, reflexos e ações positivas e negativas sobre o próprio setor florestal. A redução das oportunidades de trabalho e a regressão nas relações trabalhistas observadas pela adoção de medidas setoriais far-se-ão sentir mais cedo ou mais tarde.

A terceirização para fins de redução de custos imediatos e a concentração dos meios de produção constituem questões emergentes que devem ser discutidas em maior profundidade. Procedimentos voltados exclusivamente à melhoria imediata das condições financeiras representam não mais do que a transferência não-negociada de externalidades para outros setores da sociedade. A manutenção dos níveis atuais de competitividade por adoção de medidas imediatistas não implica, necessariamente, consolidação da posição mercadológica do setor em escala global, tampouco estabelecimento de política de desenvolvimento sustentável. Ao contrário, torna os agentes sociais envolvidos mais refratários a futuras ações integradas.

Como contrapartida à detenção de grande parte dos meios de produção, determinado setor deve, necessariamente, assumir uma perspectiva de planejamento estratégico que extrapole as fronteiras do próprio setor produtivo. Independentemente dos avanços científico-tecnológicos observados e projetados, o elemento social continuará indubitavelmente a ser fundamental e participativo de qualquer atividade produtiva. 


\section{Conclusões}

- A implementação e sustentação de um novo paradigma - desenvolvimento sustentável - está intimamente relacionado a uma predisposição política ao diálogo e à negociação, com o envolvimento direto dos diversos setores representativos da sociedade. O estabelecimento de uma nova ordem mundial predispõe os atores atuais à intensificação dos processos de negociação e procura por soluções consensadas. A fundamentação de todo o processo de desenvolvimento passa a estar diretamente relacionada ao sucesso de ações integradas, nas quais diferentes setores da sociedade tenham a oportunidade de participação nos processos decisórios e, em contrapartida, assumam postura de corresponsabilidade no gereciamento dos mesmos. Torna-se cada vez mais improvável a transferência inconteste de externalidades derivadas de determinado setor produtivo para o restante da sociedade. Ademais, a intima relação entre qualidade de vida e potencial de desenvolvimento econômico torna essencial que o setor produtivo assuma papel mais ativo no gerenciamento de processos aparentemente extrínsecos à atividade-fim. Historicamente dependentes de uma participação intensiva do Estado, as sociedades latino-americanas defrontam-se, atualmente, com a incapacidade de seus governos em gerenciar ações mais arrojadas de mudança rumo ao desenvolvimento sustentado. O surgimento de novos agentes sociais legitimamente constituídos, tal como organizações não-governamentais, apresenta-se, adicionalmente, como um dos grandes desafios políticos contrapostos ao setor empresarial. O sucesso de qualquer programa de desenvolvimento regional passa a estar diretamente condicionado à capacidade dos diferentes agentes sociais em encontrar e estabelecer estratégias de desenvolvimento que atendam às aspirações e às necessidades legítimas das parcelas diretamente afetadas.

- É necessário, no caso da América Latina, considerar as particularidades e características físicas, bióticas, econômicas e antropológicas nos processos de conceituação, planejamento e gerenciamento do desenvolvimento sustentável do setor florestal, sendo este traduzido, inclusive, pelo dimensionamento das potencialidades específicas de cada local/região. $\mathrm{O}$ estabelecimento de um conceito mais genérico de desenvolvimento sustentável não incorre na homogeneização das ações e técnicas empregadas. Ao contrário, reconhece como expressões legítimas as características culturais e ambientais. Desde que adotada no âmbito de uma negociação mais ampla, tal prerrogativa não implica retrocesso ou impedimento de programas de desenvolvimento regional. 
- O desenvolvimento e a aplicação de ciência e tecnologia na área florestal devem ser condicionados por dois aspectos: adoção de um sistema matricial de operação, de forma a permitir a implementação de ações integradas em pesquisa e desenvolvimento; consideração, de forma explícita, dos níveis de incerteza quanto ao conhecimento científicotecnológico de fenômenos e processos relacionados ao manejo florestal e ambiental. A sistemática matricial representa a adoção de uma abordagem integrada, na qual os diversos fenômenos e processos relevantes são analisados não somente quanto as suas particularidades, mas sobretudo pelo caráter sinergístico intrínseco a sistemas complexos. A integração analítica de diferentes processos representa a constatação lógica e óbvia da sistemática de interação observada tanto nos sistemas naturais quanto nos antrópicos.

- A abordagem em escala de paisagem permite a integração - de fato - das diversas variáveis ou fenômenos correlacionados ao setor florestal, proporcionando meios para a avaliação das inter-relações históricas quando da elaboração de planos de manejo ambiental. A escala de determinados fenômenos induz ao estabelecimento de estratégias de manejo que compatibilizem procedimentos analíticos às condicionantes físicas e biológicas do ambiente.

Referência bibliográficas

BURSZTYN, M. (org.) Para pensar o desenvolvimento sustentável. São Paulo, Brasiliense, 1993. $161 \mathrm{p}$.

CALDER, I.R.; HALL, R.L. \& ADLARD, P.G. Growth and water use of forest plantations. New York, Wiley, 1992. 381 p.

EHRLICH, P. R. O mecanismo da natureza. Rio de Janeiro, Campos, 1993. 328 p.

HABER, W. Basic concepts of landscape ecology and their application in land management. Physiol. Ecolo. Japan, n. 27, p. 131-146, 1990.

LIMA, W.P. Impactos ambientais do encalipto. São Paulo, EDUSP, 1994. 354 p.

REIS, M.J.L. ISO 14.000 - Riscos da certificação ambiental. Agroanálises, v. 14, n. 2, p. $48,1994$.

ROSSITER, A. Ecology, environment and economics: a pandoran perspective. Physiol. Ecol., Japan, n. 27, p. 169-189, 1990.

SELMAN, P. An investigation of the potential for landscape ecology to act as a basis for rural land plans. Journal Environ. Management, n. 35, p. 281-299, 1992. 
SHUKLA, J.B.; HALLAM, T.G. \& CAPASSO, V. (eds). Mathematical modelling of environmental and ecological systems. New York, Elsevier, 1987. 254 p.

TIGRE, P.V. (coord.). Tecnologia e meio ambiente - oportunidades para a indústria. Rio de Janeiro, URFJ, 1994. 139 p.

TURNER, M.G. Landscape ecology: the effect of pattern on process. Anmual Review Ecol. Syst., n. 20, p. 171-197, 1989.

TURNER, M.G. \& GARDNER, R.H. Quantitative methods in landscape ecology. New York, Springer-Verlag, 1991. $536 \mathrm{p}$.

Resumo

A proposta de desenvolvimento sustentado representa atualmente elemento de aprofundamento das discussões quanto ao real significado dos conceitos de progresso e desenvolvimento econômico e social. A premência por alternativas estabelecida a partir das crises ambiental e de recursos tem induzido a procura de estratégias que traduzam uma solução consistente de continuidade dos processo de desenvolvimento, sem que para isso ocorra o comprometimento da base de sustentação das atividades produtivas. As perspectivas de desenvolvimento sustentado para o setor de papel e celulose na América Latina, especificamente quanto às atividades de exploração florestal, estão intimamente relacionadas a dois aspectos fundamentais: estabelecimento de uma sistemática de negociação política entre o setor produtivo e demais representantes da sociedade; inserção dos empreendimentos dentro de uma escala mais ampla, na qual estes estejam plenamente integrados à programas de desenvolvimento regional multi-setoriais. Ademais, torna-se cada vez mais necessária a consideração de particularidades ambientais, sociais e políticas inerentes a determinado local/região. Especificamente quanto a economias e sociedades latino-americanas, o reconhecimento do contexto histórico de desenvolvimento regional constitui elemento fundamental de planejamento estratégico e de compreensão do contexto ambiental e político. O estado das artes em ciência e tecnologia, embora apresente um nível significativo de incerteza, permite a incorporação e desenvolvimento de novas estratégias de gerenciamento. A gestão ambiental, representada pelo gerenciamento de processos ambientais e produtivos de forma integrada, apresenta-se como alternativa viável de transição para um modelo de maior sustentabilidade. Programas de planejamento estratégico, aliados a sistemas dinâmicos de gerenciamento ambiental, constituem as ferramentas atualmente disponíveis para implementação e aprimoramento das sistemáticas de manejo e exploração florestal.

\section{Abstract}

Nowadays the sustainable development proposals represent a keystone in discussions of the actual meaning of the progress and social/economic development and welfare. The urgency for alternatives established by environmental and natural resources crises has induced the search for new strategies that must represent continually solution without 
threatening the sustainability of productive activities. The perspectives for sustainable development of the Latin American forest sector, specifically pulp and paper, is closed related to: the establishment of politic negotiation and trading procedures amongst this productive segment and other representative society actors; the understanding to these enterprises in a broader scale, where they must be completely integrated in multisectorial regional development programs. Also, it is very important to consider regional and local features related to social, economic and environmental states and functions. Specially considering Latin American societies it is essential to evaluate the whole process over an historic and contextual perspective. The state-of-the-art in science and technology allows the development of new concepts in management and exploitation of natural resources, although one must considers the intrinsic uncertainty levels. The sustainable management, represented by environmental processes management procedures, represents an actual alternative for transition to models of enhanced sustainability. Environmental planning programs, together with dynamic and flexible management procedures, constitute available tools to implement and improve forest and environmental management strategies.

Alexandre Grimaldi de Castro é doutorando no programa de Ciências da Engenharia Ambiental do Centro de Recursos Hídricos e Ecologia Aplicada da Escola de Engenharia de São Carlos, da Universidade de São Paulo

Sérgio Morrot, engenheiro agrônomo, é consultor independente da Morrot \& Associados Consultoria Ambiental.

Trabalho apresentado pelos autores no Programa Sustainable Paper Cycle Project, organizado pelo International Institute for Environment and Development, nos dias 9 e 10 de março de 1995. 